\title{
Impacts of Cumulus Convective Parameterization Schemes on Precipitation at Grey-Zone Resolutions: A Case Study over Complex Terrain in upper Northern Thailand
}

\author{
Sittichai Pimonsree, Phakawan Ratnamhin, Patipat Vongruang, and Sulak Sumitsawan
}

\begin{abstract}
Betts-Miller-Janji'c, Kain-Fritsch, and Grell-Devenyi cumulus convective parameterization schemes had been applied in the Weather Research and Forecasting model. This study simulated impacts of various schemes on precipitation over complex terrain in the upper Northern Thailand at grey-zone resolutions during 1-7 August 2008. The results of $3 \mathrm{~km}$ resolution show that each cumulus scheme creates different precipitation patterns reflecting the influence of cumulus scheme on the grey-zone resolution. Nevertheless, all the schemes have the capability to reasonably reproduce the main character of spatial distributions of precipitation. Detailed comparison indicates that Grell-Devenyi scheme and the ensemble of three schemes give a better performance of simulating spatial pattern than the other cumulus schemes.
\end{abstract}

Index Terms - Cumulus parameterization schemes, grey-zone resolutions, precipitation, complex terrain, WRF.

\section{INTRODUCTION}

Precipitation data is important for agricultural planning, water resource management, public works, and tourisms. The lacking of observed rainfall data, especially in complex terrain is common since the rain gauge in mountainous area is sparse. As a result, the employment of meteorological models in predicting precipitation data is beneficial in the area that is lack of monitoring data. Cumulus Convective Parameterization Schemes (CP) is a key parameter for rainfall prediction [1]. Various CP schemes have been developed to account for the collective effects of ensembles of discrete convective bubbles or plumes. Since most CP schemes assume that deep convection only occupies a very small part of a grid, $\mathrm{CP}$ is normally applied at grid scales exceeding $\sim 10$ $\mathrm{km}$. [2]. The necessity of CP for numerical predictions of convective weather at high resolutions, where deep convection is partly resolved and partly subgrid continues to be questioned. [3] Used the term "grey-zone resolution" to represent this type of resolution. It is crucial to find the most suitable convective parameterization scheme for a certain region at a given resolution. A number of researches have studied on the impacts of convective parameterization schemes on precipitation [4]-[6] However, there are limited works that studied the influence of $\mathrm{CP}$ in grey-zone resolution Therefore, this work investigated the influence of the

Manuscript received April 26, 2015; revised June 27, 2015.

The authors are with the School of Energy and Environment, University of Phayao, Phayao, Thailand (e-mail: sittichai007@hotmail.com, arvakee_eiei@hotmail.com, sulak.sumit@gmail.com).
Betts-Miller-Janji'c, Kain-Fritsch, and Grell-Devenyi cumulus parameterization schemes on precipitation simulation in grey-zone resolution over Northern Thailand using the Weather Research and Forecasting (WRF) model.

\section{METHODOLOGY}

This study investigated the influence of $\mathrm{CP}$ on moderate and heavy rainfall in Northern Thailand during 1-7 August 2008. The simulations were performed on three nested domains (Fig. 1). The finest domain covers the entire area of Northern Thailand (Fig. 1) with grey-zone resolution of $3 \mathrm{~km}$. The detail of model configuration is shown in Table I. Three convective schemes, namely, Kain-Fritsch (KF; [7], [8]), Betts-Miller, modified further by Janji'c (BMJ; [9], [10]), and Grell-Devenyi (GD; [11]) are employed. The ensemble results of the three schemes (ENS) are also investigated. Model results were compared to 55-observed rainfall dataset. The rain gauge sites which observed data was obtained are shown in Fig. 2. Moreover, the simulated precipitations were evaluated with the daily gridded rainfall data of Tropical Rainfall Measuring Mission (TRMM) estimated using satellite dataset. The grid resolution of TRMM dataset is about $25 \mathrm{~km}$. Spatial correlation coefficient (R), bias and root mean square error (RMSE) are used to evaluate the capacity of the model.

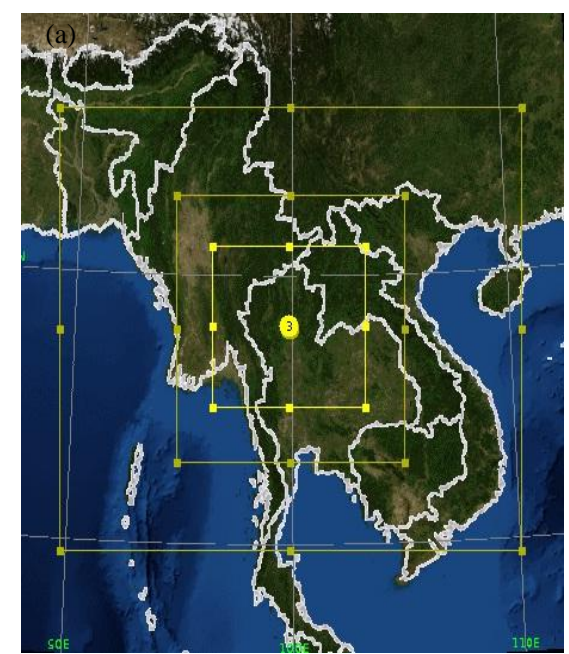

Fig. 1. Location of modeling domains 1, 2 and 3, which have horizontal resolutions of 27,9 , and $3 \mathrm{~km}$, respectively.

Precipitation maps were generated by Kriging interpolation method using observed rainfall data from 55 rain gauges, TRMM rainfall map was generated by using grid dataset (grid resolution $25 \mathrm{~km}$.) which obtained from satellite, and 
simulated rainfall map using every grid dataset (grid resolution $3 \mathrm{~km}$.) from WRF model in Northern Thailand.

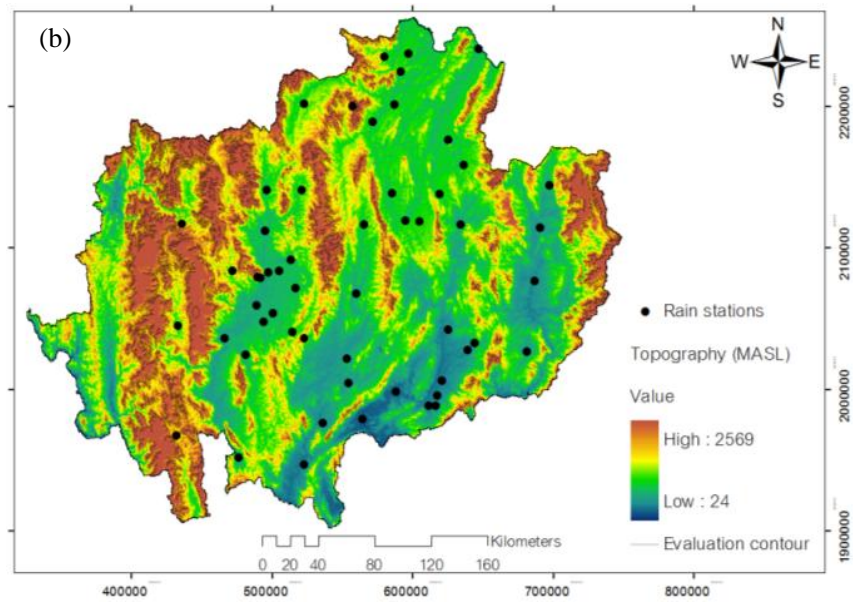

Fig. 2. Topography and rain gauge sites in Northern Thailand.

TABLE I: DETAILS OF WRF MODEL CONFIGURATION

\begin{tabular}{ll}
\hline Parameters & Model Configuration \\
\hline Horizontal grids & $\mathrm{D} 1=80 \times 80, \mathrm{D} 2=148 \times 148, \mathrm{D} 3=250 \times 250$ \\
Horizontal resolution & $\mathrm{D} 1=27 \mathrm{~km}, \mathrm{D} 2=9 \mathrm{~km}, \mathrm{D} 3=3 \mathrm{~km}$ \\
Microphysics scheme & WRF Single-Moment (WSM) 6-class graupel \\
& scheme \\
1. No Cumulus scheme (noCP) & 2. Kain-Fritsch (KF) \\
& 3. Betts-Miller-Janjic (BMJ) \\
& 4. Grell-Devenyi (GD) \\
& Yonsei University (YSU) \\
PLB scheme & Radiation The Rapid Radiative Transfer Model \\
Long-wave radiation & (RRTM) scheme \\
Short-wave radiation & Dudhia (1989) scheme \\
Surface layer & MM5 similarity: Monin-Obukhov similarity \\
& theory \\
Land surface & 5-layer thermal diffusion from MM5 \\
\hline
\end{tabular}

\section{RESULTS AND DISCUSSION}

Fig. 4 demonstrates the distribution of the observed and simulated 7-days accumulated precipitation during 1-7 August 2008. Precipitation decreases from northeast to southwest over Northern Thailand. Generally, WRF performs well capturing of this signal and reproduces the geographical pattern. However, statistical comparison in Table II and Fig. 3 shows positive bias indicating that WRF overestimates in the study area. Simulated precipitation is high in southwest region because of significant topographic effects which cause upslope motions of southwest monsoon systems. Low precipitation in southwest region of monitoring map could be due to no observed data in this area. High precipitation near southwest boundary of Northern Thailand is also found in TRMM map (not shown here).

When considering precipitation map in detail, the different rainfall distributions were found among different cumulus schemes. No cumulus scheme was unable to reproduce the spatial distribution of precipitation well. The spatial correlation coefficient of noCP is only 0.29 . The results reflect that simulated precipitations in grey-zone resolution over complex terrain are the results of not only grid resolved, but also the influence of Cumulus Convective Parameterization. The cumulus parameters should be used to predict precipitation at Grey-Zone Resolutions over complex terrain.

Statistical comparison between three convective schemes show that simulated rainfall distribution by GD scheme is closest to observed precipitation with spatial correlation coefficient 0.63 and RMSE 13.7. The comparison between precipitation from WRF and the observation at monitoring point found that BMJ generates higher precipitation compared to other cumulus schemes. Table II and Fig. 3 show statistical data of BMJ evaluation with average weekly precipitation of $81 \mathrm{~mm}$. (more than the observation 56\%), RMSE 17.8, bias 4.2. BMJ predicts poor rainfall distribution with spatial correlation coefficient only 0.37 . GD and KF scheme performs better than BMJ in simulating precipitation with RMSE 13.7 and 14.5 respectively. The ensemble of three schemes provides the lowest RMSE of 12.3 and highest spatial correlation coefficient of 0.64 . Therefore, ensemble is the suitable way to simulate precipitation because one $\mathrm{CP}$ scheme cannot simulate every atmospheric process.

TABLE II: STATISTICAL COMPARISON BETWEEN PRECIPITATION FROM WRF, TRMM, AND OBSERVATIONS FOR 55 DATASET AT MONITORING POINT (FOR WRF AND TRMM Using DATA FROM GRID AT THE SAME MONITORING POINT)

\begin{tabular}{lccccc}
\hline & NoCPS & KF & BMJ & GD & Ensemble \\
\hline RMSE & 14.4 & 14.5 & 17.8 & 13.7 & 12.3 \\
Bias & -1.34 & 1.6 & 4.2 & 2.6 & 2.8 \\
$\begin{array}{l}\text { Spatial } \\
\text { correlation } \\
\text { coefficient }\end{array}$ & 0.29 & 0.57 & 0.37 & 0.63 & 0.64 \\
\hline
\end{tabular}

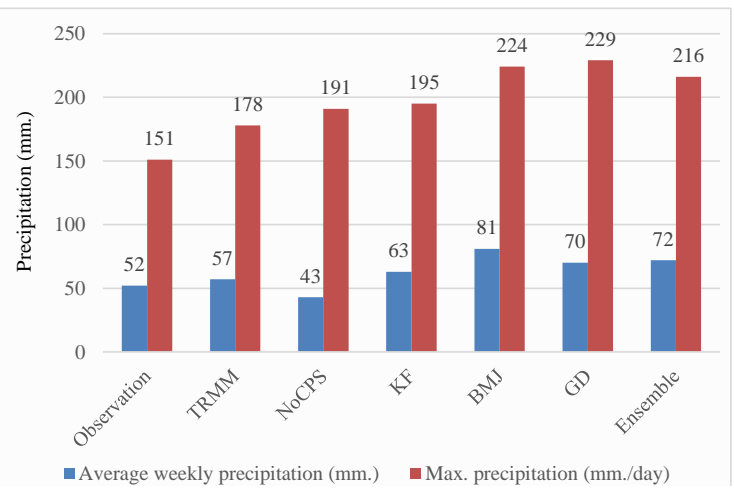

Fig. 3. Average weekly precipitation $(\mathrm{mm}$.) and maximum precipitation (mm/day) from WRF, TRMM, and observations for 55 dataset at monitoring point (for WRF and TRMM using data from grid at the same monitoring point).

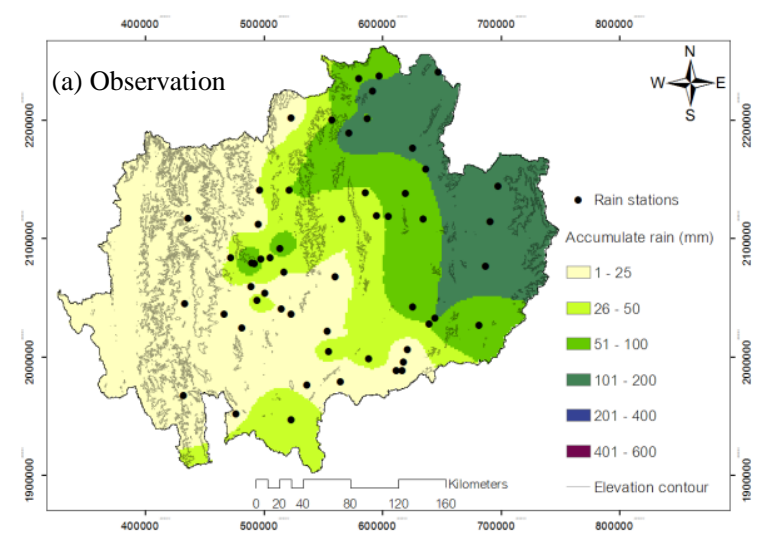



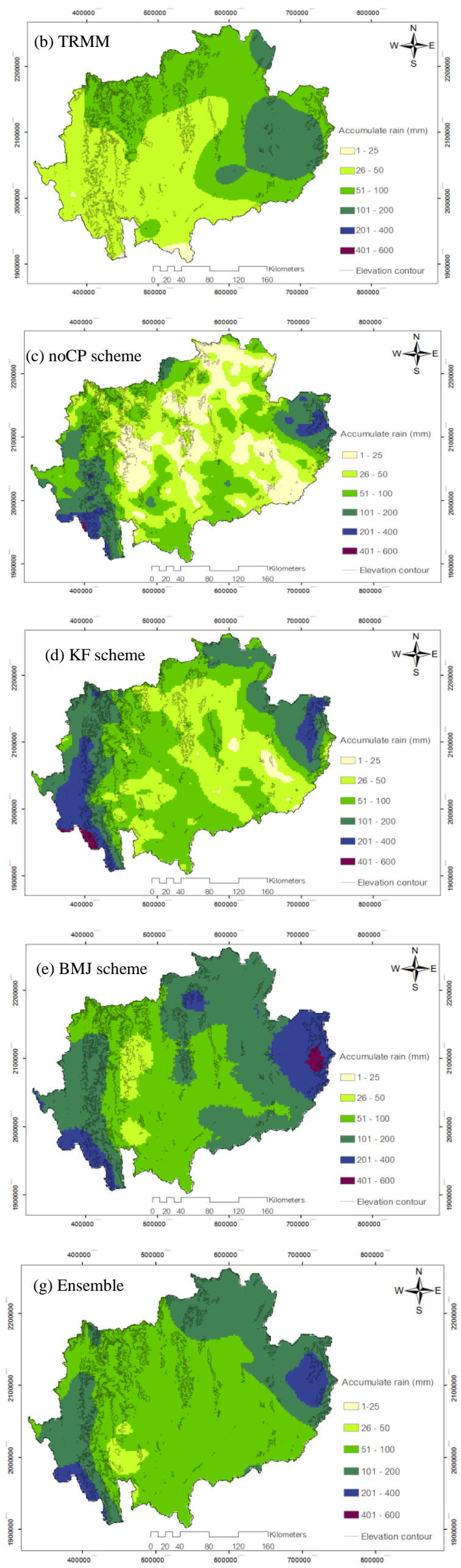

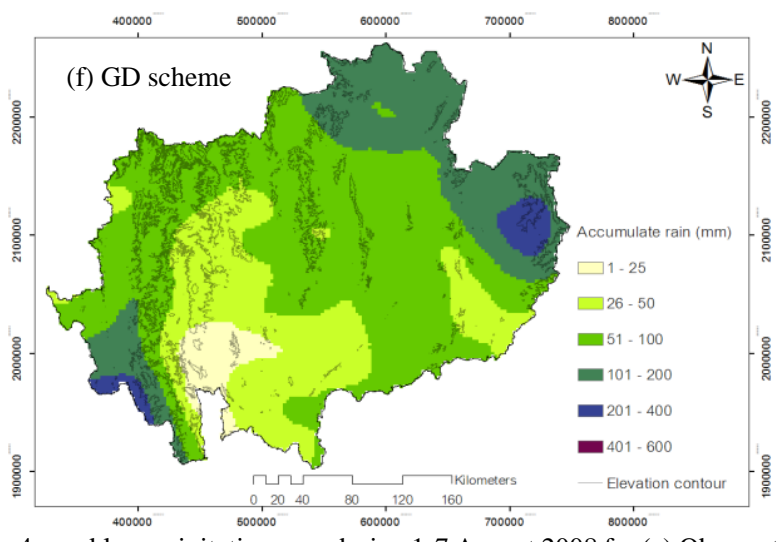

Fig. 4. weekly precipitation map during 1-7 August 2008 for (a) Observation (b) TRMM (c) No cumulus scheme (d) KF scheme (e) BMJ scheme (f) GD scheme $(\mathrm{g})$ Ensemble of the three schemes.

\section{CONCLUSION}

This paper investigates the impacts of several different cumulus schemes on precipitation simulation at Grey-Zone Resolutions over complex terrain in upper Northern Thailand using the WRF model. The results reveal that the simulated precipitation at $3 \mathrm{~km}$. grid resolution requires a $\mathrm{CP}$ to represent the sub-grid scale convection and precipitation. Generally, all three cumulus schemes have the capability to reproduce the main character of spatial distributions of precipitation in Northern Thailand while positive bias was found in all $\mathrm{CP}$ schemes. However, three $\mathrm{CP}$ provided different precipitation pattern in detail and difference in quantity of rainfall simulation. The results from this study imply that the application of meso-scale meteorological model for simulating precipitation at grey-zone resolutions should account for Cumulus Convective Parameterization Schemes for better simulated precipitation in high resolution grid scale over complex terrain. The GD scheme shows a better performance of simulating spatial distribution compared with the other cumulus schemes. The ensemble of three schemes gives the best performance. Therefore, the ensemble of CP schemes is highly capable to simulate precipitation since the processor is now well developed.

\section{ACKNOWLEDGMENT}

Acknowledge NCEP/NOAA for the public access of FNL data used in the study. WRF model was obtained from NCAR, USA. The observations used in the study were obtained from Hydrology and water management center for upper northern region (Chiang Mai Thailand). Authors acknowledge the satellite precipitation data supported by NASA/TRMM. Thanks are due to anonymous was reviewers for their technical comments which helped to improve the manuscript.

\section{REFERENCES}

[1] Y. M. Liu and Y. H. Ding, "Modified mass flux cumulus parameterization scheme and its simulation experiment. Part I: Mass flux scheme and its simulation of the 1991 flooding in China," Acta Meteor. Sinica, vol. 59, pp. 10-22, 2001.

[2] J. M. Molinari and M. Dudek, "Parameterization of convective precipitation in mesoscale numerical models: A critical review," Mon.Wea. Rev, vol. 120, pp. 326-344, 1992.

[3] L. Gerard, "An integrated package for subgrid convection, clouds and precipitation compatible with meso-gamma scales," Quart. J. Roy. Meteor. Soc, vol. 133, pp. 711-730, 2007. 
[4] X. Z. Liang, M. Xu, K. E. Kunkel et al., "Regional climate model simulation of U.S.-Mexico summer precipitation using the optimal ensemble of two cumulus parameterizations," J. Climate, vol. 20, no. 20, pp. 5201-5207, 2007.

[5] P. Mukhopadhyay, S. Taraphdar, B. N. Goswamet et al., "Indian summer monsoon precipitation climatology in a high-resolution regional climate model: Impacts of convective parameterization on systematic biases," Wea. Forecasting, vol. 25, no. 2, pp. 369-387, 2010.

[6] M. Gu and A. N. Huang, "Effects of cumulus convective parameterization on the precipitation simulation over eastern China with the p- $\sigma$ RCM9 regional climate model," Scientia Meteorologica Sinica, vol. 28, no. 5, pp. 488-493, 2008.

[7] J. S. Kain, "The Kain-Fritsch convective parameterization: An update," J. Appl. Meteorol, vo. 43, no. 1, pp. 170-181, 2004.

[8] J. S. Kain and J. M. Fritsch, "Convective parameterization for mesoscale models: The Kain-Fritsch scheme, the representation of cumulus convection in numerical models," Meteor. Monogr, vol. 46 , pp. $165-170,1993$.

[9] A. K. Betts, "A new convective adjustment scheme. Part I: Observational and theoretical basis," Quart. J. Roy. Meteor. Soc, vol. 112 , pp. 677-691, 1986

[10] A. K. Betts and M. J. Miller, "A new convective adjustment scheme. Part II: Single column tests using GATE wave, BOMEX, and arctic air-mass datasets," Quart. J. Roy. Meteor. Soc, vol. 112, pp. 693-709, 1986.

[11] G. Grell and D. Devenyi, "A generalized approach to parameterizing convection combining ensemble and data assimilation techniques," Geophys. Res.Lett, vol. 29, no. 14, pp. 38-31, 2002.

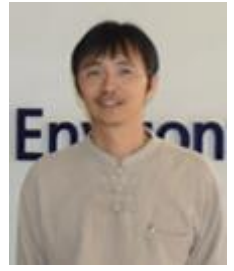

Pimonsree Sittichai got the $\mathrm{PhD}$ degree in 2009 in environmental technology, the Joint Graduate School of Energy and Environment, King Mongkut's University of Technology, Thailand. He received his M.Eng. in environmental engineering in 2000 and the B.Eng. in mechanical engineering in 1994, Chiang Mai University, Thailand. Since 2008 he has been a lecturer in Environmental Engineering Department at
University of Phayao. He was the head of Environmental Engineering Department in 2013 and continued till he occupied the position of the vice dean for Academic at School of Energy and Environment. His major research interests are in air pollution, weather and climate change in Southeast Asia using atmospheric modeling system.

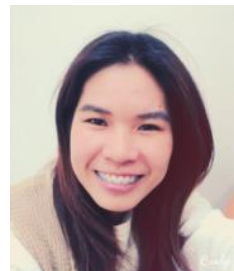

P. Ratnamhin received the B.S. degree in chemistry from the Naresuan university and the master degree in environmental engineering from the University of Phayao, Thailand. Her research focuses on cumulus convective parameterization schemes on precipitation over complex terrain in upper Northern Thailand

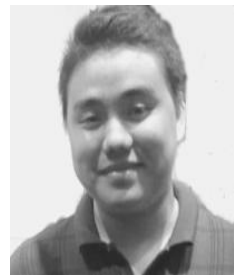

P. Vongruang received the B.S. degree in chemistry from the Naresuan university and the M.S. degree in environmental engineering from the University of Phayao. He is currently a Ph.D. student in the environmental technology from the University of Phayao. His past research included biomass burning emission and mesoscale meteorology models. His current research focuses on the chemistry transport model to study air quality from biomass burning in Upper Southeast Asian.

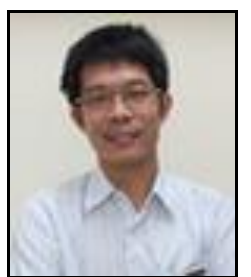

S. Sumitsawan received his Ph.D. degree in civil engineering from University of Texas at Arlington, Texas USA and received his M.Eng and B.Eng in environmental engineering from Chiangmai University, Thailand. His research focus is currently in black carbon, photocatalytic oxidation of volatile organic compounds, and transportation emissions. 